\title{
Correction to: Fruits of the Veld: Ecological and Socioeconomic Patterns of Natural Resource Use across South Africa
}

\author{
Mallika Sardeshpande $^{1}$ (D) $\cdot$ Charlie Shackleton ${ }^{1}$ \\ Published online: 12 November 2020 \\ (C) Springer Science+Business Media, LLC, part of Springer Nature 2020
}

\section{Correction to: Human Ecology}

https://doi.org/10.1007/s10745-020-00185-x

The Conflict of Interest statement in the original publication unfortunately contained a mistake. The original article has been corrected.

Publisher's Note Springer Nature remains neutral with regard to jurisdictional claims in published maps and institutional affiliations.

The online version of the original article can be found at https://doi.org/ 10.1007/s10745-020-00185-x

Mallika Sardeshpande

mallika.sardeshpande@gmail.com

Charlie Shackleton

c.shackleton@ru.ac.za

1 Department of Environmental Science, Rhodes University, Makhanda, (Grahamstown) 6140, South Africa 